http://jmscr.igmpublication.org/home/ ISSN (e)-2347-176x ISSN (p) 2455-0450

crossref DOI: https://dx.doi.org/10.18535/jmscr/v7i11.83

Journal Of Medical Science And Clinical Research

\title{
Study of Secondary Lung Infections in Newly Diagnosed Pulmonary Tuberculosis
}

\author{
Authors \\ Dr Anila Jose ${ }^{1 *}$, Dr R Vedavathi ${ }^{2}$, Dr Preethi R Gandhi ${ }^{3}$, Dr Tharuni Latha. ${ }^{4}$, \\ Dr Hilas, Dr Vijaykumar S $\mathbf{S}^{6}$ \\ ${ }^{1}$ Junior Resident, Department of General Medicine, KIMS Hospital, Bangalore \\ ${ }^{2}$ Professor, Department of General Medicine, KIMS, Bangalore \\ ${ }^{3,4,5,6}$ Junior Resident, Department of General medicine, KIMS, Bangalore
}

Kempegowda Institute of Medical Sciences and Research Centre, V.V. Puram, Bangalore, 560004

*Corresponding Author

Dr Anila Jose

Junior Resident, Department of General Medicine, KIMS, Bangalore, India

\begin{abstract}
Background: Tuberculosis (TB) is one of the most highly infectious diseases in India. Secondary lung infection is one of the most important complications in patients with pulmonary tuberculosis. However, very little literature is available regarding secondary lung infections in pulmonary tuberculosis and hence, the need for our study.

Aims and Objectives: To determine the pathogenic organisms causing secondary lung infection in newly diagnosed pulmonary tuberculosis and to determine the antibiotic susceptibility pattern among bacterial pathogens

Methods: Sputum samples or BAL samples of the patients who are highly suspicious of pulmonary tuberculosis by history, clinical examination and, radiological evaluation has been collected and send for sputum AFB, gram staining, bacterial culture sensitivity and, fungal culture. Only AFB positive samples have been included in the study. Bacteria were identified according to standard microbiological techniques. The results of the gram stain, culture along with culture sensitivity pattern of bacteria has been recorded.

Results: Of 100 patients included in the study, $20 \%$ of patients have a secondary infection. Among those who have secondary infection $90 \%$ is male population and rest $10 \%$ only is seen in females. The most common risk factor found to be smoking / Chola inhalation ( $80 \%$ ) and the next common risk factor was found to be diabetes mellitus (55\%). $65 \%$ of secondary infection was bacterial whereas $35 \%$ was found to be the fungal infection. The most common secondary bacterial infection in newly detected pulmonary TB is found to be Klebsiella (53.89\%). It is also found to have Gentamycin is the most sensitive antibiotic.

Conclusion: In our study, the most common secondary infection is Klebsiella pneumonia and the most effective antibiotic was found to be Gentamycin. Since it was found that $20 \%$ of patients have secondary lung infection; we have to send for sputum culture sensitivity for all patients who have been diagnosed with pulmonary tuberculosis and appropriate antibiotic treatment will prevent further complications.

Keywords: secondary lung infection, tuberculosis.
\end{abstract}

\section{Introduction}

Tuberculosis is one of the most contagious

diseases in India which is caused by
Mycobacterium Tuberculosis ${ }^{1}$. It's an age-old disease and the organism was described by Hermann Heinrich Robert Koch on March 24, 
1882, and hence Mycobacterium tuberculosis is also called as Koch's bacilli. ${ }^{2}$ It is found that pulmonary tuberculosis patients can have secondary infections but the significance of these potentially pathogenic organisms is uncertain. ${ }^{3}$ In certain studies, it has been found that secondary infection in tuberculosis may delay the curing time of tuberculosis and can result in so many complications which include multi-drug resistance ${ }^{4}$.

\section{Materials and Methods}

Source of Data: Patients who are admitted to the Kempegowda Institute of Medical Science and hospital, Bengaluru with newly diagnosed pulmonary tuberculosis.

Duration of the Study: 18 months (December 2017- May 2019)

Sample Size: 100 subjects

Type of Study: Retrospective study. Inclusion Criteria

Age> 18 years
Newly detected sputum positive pulmonary tuberculosis

\section{Exclusion Criteria}

Patients already on ATT

\section{Method of Collection of Data}

Patients who were admitted with clinical suspicion of tuberculosis with proper history and clinical examination have been asked for sputum AFB. Those cases which were found to have AFB positive ie; newly diagnosed pulmonary tuberculosis has been asked for sputum culture and sensitivity. The results were recorded and analyzed.

\section{Results}

Incidence

Out of 100 subjects who were diagnosed to have pulmonary tuberculosis, only 20 people have been found to have a secondary lung infection. The incidence of secondary lung infection is $20 \%$.

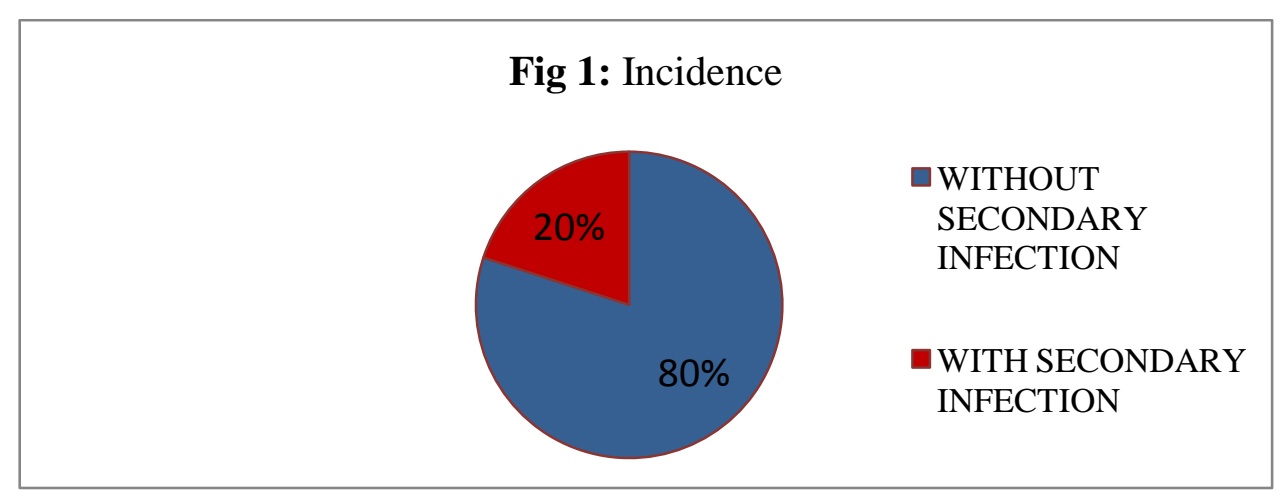

Fig 2: Age and Sex Distribution

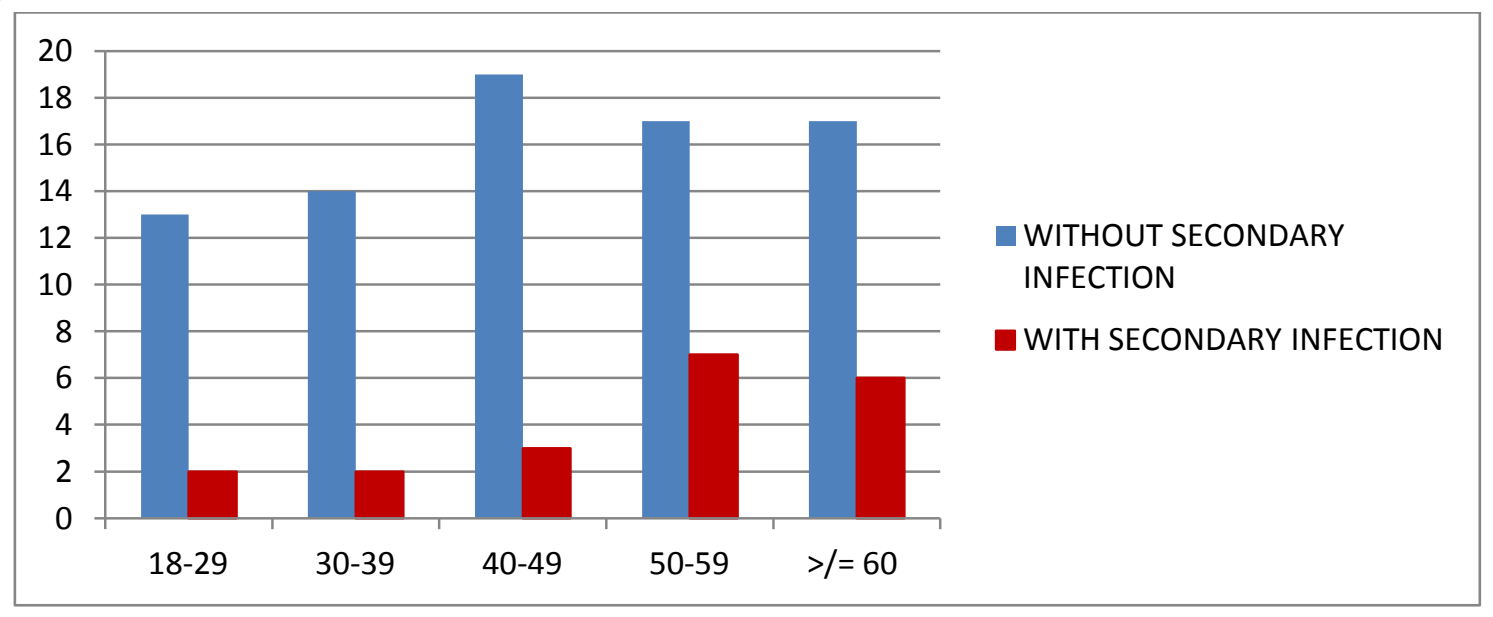


It was found in our study that tuberculosis is most commonly seen in males $(76 \%)$ than in females $(24 \%)$. It has been found that the ratio of male: female was 18:2, in case of secondary infections.
It has also been found in our study that secondary infections are mostly seen in elderly people $>50$ years ie; 13 out of 20 people where above 50 years $(65 \%)$.

Fig 3: Risk Factors

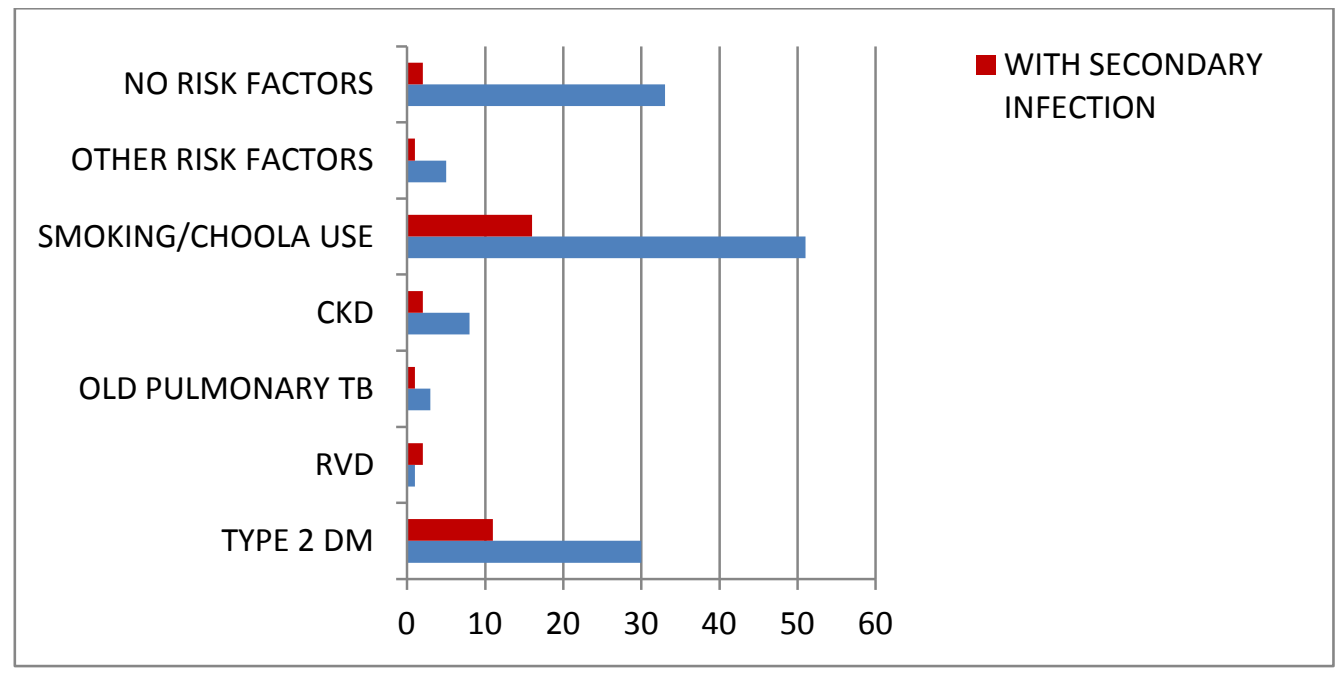

The most common risk factor for secondary infection was found to be smoking / Chola use $(80 \%)$ of patients and the second most common

Fig 4: Secondary Lung Infection

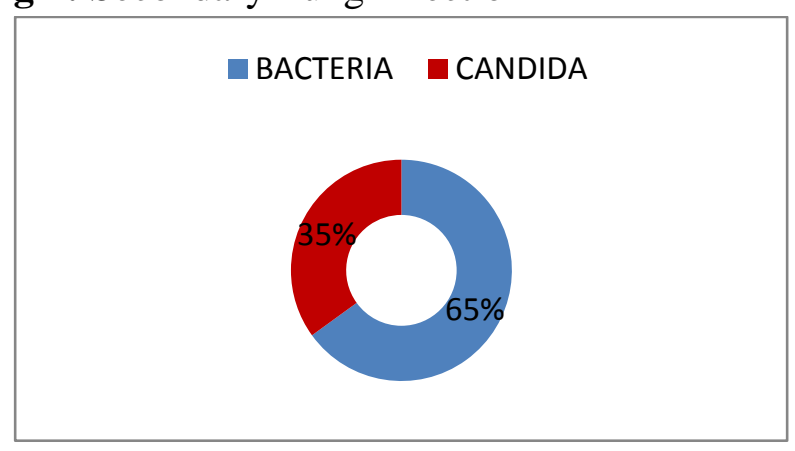

being diabetes mellitus accounting for about $55 \%$ of cases.

It has been found that out of 100 patients only 20 patients had a secondary infection. Out of the 20 patients who had lung infection 13 patients had bacterial infection whereas 13 patients suffered from fungal infection.

Fig 5: Organism Growth

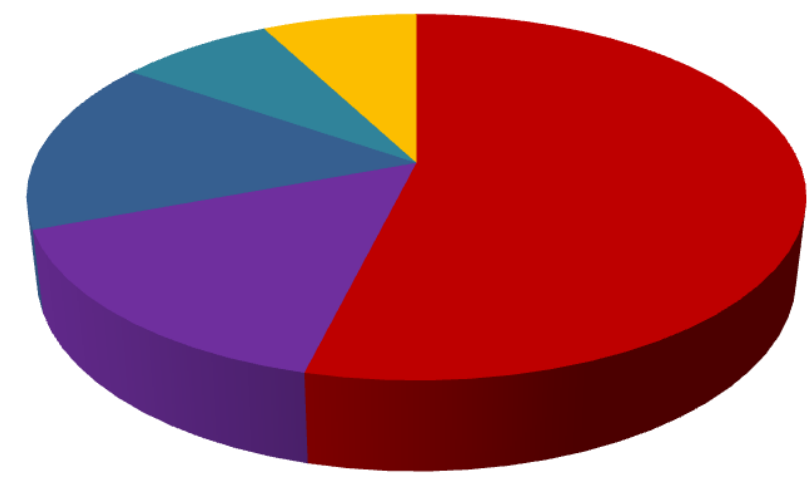


Among patients who had bacterial infections, it was found that $53.84 \%$ were due to Klebsiella pneumoniae, $15.38 \%$ each were due to

Table 1: Comparison of Antibiotic Susceptibility

\begin{tabular}{|l}
\hline Cefoperazone \\
\hline Ceftriaxone/Tazobactum \\
\hline Cefuroxime \\
\hline Cefepime \\
\hline Cotrimoxazole \\
\hline Clindamycin \\
\hline Cloxacillin \\
\hline Erythromycin \\
\hline Ciprofloxacin \\
\hline Gentamycin \\
\hline Levofloxacin \\
\hline Linezolid \\
\hline Tetracyclin \\
\hline Vancomycin \\
\hline Amikacin \\
\hline Imipenam \\
\hline Meropenam \\
\hline PIP/TAZ \\
\hline
\end{tabular}

\begin{tabular}{|c|}
\hline Staphylococcus \\
\hline $100 \%$ \\
\hline $\mathrm{R}$ \\
\hline $\mathrm{R}$ \\
\hline $\mathrm{R}$ \\
\hline $\mathrm{R}$ \\
\hline $100 \%$ \\
\hline $100 \%$ \\
\hline $100 \%$ \\
\hline $\mathrm{R}$ \\
\hline $100 \%$ \\
\hline $\mathrm{R}$ \\
\hline $100 \%$ \\
\hline $100 \%$ \\
\hline $50 \%$ \\
$\mathrm{R}$ \\
$\mathrm{R}$ \\
$\mathrm{R}$ \\
\hline $\mathrm{R}$
\end{tabular}

Klebsiella pneumonia, which was the most common isolated organism in a case of newly detected pulmonary tuberculosis was $100 \%$ sensitive to gentamycin, amikacin and, meropenem. It has also been found in our study that all organisms which had cause secondary bacterial infection were sensitive to Gentamycin. The most resistant organism in our study was found to be Pseudomonas which was resistant to all antibiotics except gentamycin, amikacin, imipenem, meropenem and, piperacillin tazobactum.

\section{Discussion}

Pulmonary tuberculosis can be associated with secondary infection and secondary bacterial infection is one of the most common complications of pulmonary tuberculosis. ${ }^{5}$ Our study population included 100 patients who were found to have newly diagnosed pulmonary tuberculosis in which $20 \%$ suffered from a secondary lung infection. The major age group who had suffered from secondary lung infection
Staphylococcus aureus \& Pseudomonas and $7.69 \%$ each were due to Enterococcus and Ecoli.

\begin{tabular}{|c|c|c|c|}
\hline Klebsiella & E Coli & Pseudomonas & Enterococcus \\
\hline $42.85 \%$ & $\mathrm{R}$ & $\mathrm{R}$ & $\mathrm{R}$ \\
\hline $71.42 \%$ & $100 \%$ & $\mathrm{R}$ & $\mathrm{R}$ \\
\hline $28.57 \%$ & $\mathrm{R}$ & $\mathrm{R}$ & $\mathrm{R}$ \\
\hline $42.85 \%$ & $100 \%$ & $\mathrm{R}$ & $100 \%$ \\
\hline $57.14 \%$ & $\mathrm{R}$ & $\mathrm{R}$ & $\mathrm{R}$ \\
\hline $\mathrm{R}$ & $\mathrm{R}$ & $\mathrm{R}$ & $100 \%$ \\
\hline $\mathrm{R}$ & $\mathrm{R}$ & $\mathrm{R}$ & $\mathrm{R}$ \\
\hline $\mathrm{R}$ & $\mathrm{R}$ & $\mathrm{R}$ & $100 \%$ \\
\hline $85.71 \%$ & $\mathrm{R}$ & $\mathrm{R}$ & $100 \%$ \\
\hline $100 \%$ & $100 \%$ & $100 \%$ & $100 \%$ \\
\hline $71.42 \%$ & $\mathrm{R}$ & $\mathrm{R}$ & $\mathrm{R}$ \\
\hline $\mathrm{R}$ & $\mathrm{R}$ & $\mathrm{R}$ & $100 \%$ \\
\hline $\mathrm{R}$ & $\mathrm{R}$ & $\mathrm{R}$ & $100 \%$ \\
\hline $\mathrm{R}$ & $\mathrm{R}$ & $\mathrm{R}$ & $100 \%$ \\
\hline $100 \%$ & $100 \%$ & $100 \%$ & $\mathrm{R}$ \\
\hline $71.42 \%$ & $100 \%$ & $100 \%$ & $\mathrm{R}$ \\
\hline $100 \%$ & $100 \%$ & $100 \%$ & $\mathrm{R}$ \\
\hline $85.71 \%$ & $100 \%$ & $50 \%$ & $\mathrm{R}$ \\
\hline
\end{tabular}

was more than 50 years. Male: female ratio of patients who developed tuberculosis was 74:26 whereas the ratio in patients who developed secondary infection was 18:2.

The most common risk factor for secondary infection in our study was smoking/ Chola use. Smoking or Chola use causes structural changes in the respiratory tract and decrease in immune response which predisposes to secondary lung infection ${ }^{6}$. The other main risk factor was diabetes mellitus which is an immunosuppressive state and hence they are prone for infections.

The most common organism isolated being Klebsiella pneumonia which is Gram - Negative, non-motile bacillus which results in the necrotizing inflammatory process leading to "red currant jelly sputum". Usually, Klebsiella pneumonia causes the cavitary lesion in lung. ${ }^{7}$ Tuberculosis itself is an immunocompromised state that can predispose to fungal infection and the fungus which has grown in the culture in our study being Candida albicans. 
Gentamycin is an aminoglycoside antibiotic that is being used in the treatment of severe Gram Negative infections. In our study, we found the most effective antibiotic which can be used in cases of secondary infection in pulmonary tuberculosis is gentamycin. However, the most common side effect of Gentamycin is nephrotoxicity ${ }^{8}$.

Zakaria et al., in 2013 studied "on the current Status of secondary Infection of Pulmonary T.B."; found that among $450 \mathrm{~TB}$ suspected patients 100 samples were cultured for isolating secondary bacterial infection of newly detected pulmonary TB (PTB) patients whose are already treated by TB drugs. From these cultured samples, 22 were isolated as Klebsiella spp and 10 were isolated as Staphylococus ${ }^{4}$.

Table 2: Comparative Study

\begin{tabular}{|l|c|c|}
\hline & $\begin{array}{c}\text { Zakaria et al., } \\
\mathbf{2 0 1 3}\end{array}$ & Our study \\
\hline Total number & 450 & 100 \\
\hline Male:Female & $68: 32$ & $74: 26$ \\
\hline Culture positive & 100 & 20 \\
\hline Percentage common & $22.22 \%$ & $20 \%$ \\
\hline $\begin{array}{l}\text { Most Klebsiella } \\
\text { bacterial pathogen }\end{array}$ & \begin{tabular}{c} 
Klebsiella \\
\hline $\begin{array}{l}\text { Most sensitive } \\
\text { antibiotic }\end{array}$
\end{tabular} & $\begin{array}{c}\text { Centamycin } \\
\text { Nalidixic acid }\end{array}$ \\
\hline
\end{tabular}

When compared with Zakaria et al; 2013 it has been found that our study can be compared with their study. The percentage of secondary infection in Zakaria et al was $22.22 \%$ whereas in ours the percentage of secondary infection was $20 \%$. The most common organism isolated in both the studies was Klebsiella and the most effective antibiotic was Gentamycin in both the studies.

\section{Limitations}

Since we have studied the culture sensitivity in patients who are newly detected to have tuberculosis, it was difficult to say whether the patient was having a secondary infection or the patient was having a co-infection. The other limitations of our study were being a single-center study, short duration and non-assessment of infection whether community or hospital-acquired infection.

\section{Conclusion}

In our study, we found that about $20 \%$ of newly detected sputum positive pulmonary tuberculosis is associated with secondary infection. Most of the secondary infection was associated with a bacterial infection. Among the bacterias, most were Gram-Negative. Among the Gram-Negative bacterias, Klebsiella was the most common one. All organisms were found to be sensitive to Gentamycin. The most resistant organism was found to be Pseudomonas aeruginosa.

\section{Bibliography}

1. Barberis, N.L Bragazzi, L. Galluzzo, et al The history of tuberculosis: from the first historical records to the isolation of Koch's bacillus. J PREV MED HYG 2017; 58: E9-E12

2. Thomas M Daniel et al The History Of Tuberculosis: Respiratory Medicine (2006) 100.1862-1870

3. E Shaddock (Cert in Pulmonology, Cert in Crit Care, Consultant), N Bosman (Consultant), $\mathrm{T}$ Nana (Consultant) \& $\mathrm{C}$ Feldman (Principal Specialist, Head of Department) Southern African Journal of Infectious Diseases, 29:1， 23-26 https://doi.org/10.1080/23120053.2014.11 441562

4. MD. JOYNAL ABEDIN KHAN \& ZAKARIA AHMED International Journal of General Medicine and Pharmacy (IJGMP);ISSN 2319-3999; Vol. 2, Issue 2, May 2013, 11-16

5. Amaryllis Langbang1, Nabajit Deka, Hafizur Rahman1 and Devjyoti Kalita et al Int. J.Curr. Microbiol. App.Sci(2016) 5(8): 197-203

6. Lidia Arcavi, Neal L. Benowitz, et al cigarette smoking and infection Arch Intern Med. 2004;164:2206-2216 
7. Simon E. Prince, MS, Karen Ann Dominger, Burke A. Cunha and Natalie C. Klein et al Klebsiella pneumoniae pneumonia,

https://doi.org/10.1016/S01479563(97)90028-5

8. Nazia Begum, Vasudha Bakshi, Vijayalaxmi A, Devender Gaud P , K Sunand, K Sharath Kumar, Sana et al Protective Role of Piperine and Metformin on Gentamicin Induced Hepatorenal Toxicity ,Int. J. Pharm. Sci. Rev. Res., 35(2), November - December 2015; Article No. 16, Pages: 83-89. 